\title{
ASSESSING EDUCATIONAL OUTCOMES: ANOTHER HURDLE IN THE ACCREDITATION PROCESS?
}

Henry R. Lehrer, Ph.D.

Embry-Riddle Aeronautical University

\begin{abstract}
Universities and colleges that have aviation programs have a unique mission; such programs have a primary purpose of providing graduates for productive careers in aviation and aerospace. In addition, many if not most programs are approved by the Federal Aviation Administration (FAA) and are specifically taught to meet performance objectives contained in the appropriate Federal Aviation Regulations (FARs). But meeting such performance objectives may not be sufficient to meet the future demands of regional accreditation agencies. This paper is an overview of the institutional effectiveness movement, preparing for an accreditation visit, academic change, assisting faculty members to prepare performance objectives, and integrating academic programs that embrace the FARs, the academic traditions of the aviation program, and the unique and highly technical background of the faculty.
\end{abstract}

\section{Background}

What skills, knowledge, and values does or possibly should a well educated college graduate possess? Does a college education make a difference in obtaining these attributes or could an individual prepare just as well for the demands or entry requirements of the work place in another manner? Such issues have become more important in the past few years as the question of outcomes assessment or institutional effectiveness has emerged as a critical issue in academe.

Regional accreditation associations are also becoming increasingly interested in not only assessment procedures and the administration of such procedures, but are also placing considerable emphasis on the use of assessment findings for program evaluation. North Central Association of Colleges and Schools Executive Director Patricia Thrash (1991) stated that "the time has come for regional accreditation to assume a more active, visible role [and the director would] . . . . like to see more recognition of the substantial efforts the regionals are making to provide increased assurance of educational quality and a greater assurance to institutions for their improvement (pp. 6-7)." Stephen Weiner (1991), Executive Director of the Western Association of Schools and Colleges, stated that "regional accreditors look both at how well each college or university accomplishes its proclaimed purposes and whether each institution meets the general standards of the community of higher education" (p. 7).

As early as 1973, at Alverno College or in 1976 with the American Assembly of Collegiate Schools of Business (AACSB) Outcomes Measurement Project, educators have become increasingly concerned with whether students have mastered the basic information, attitudes, and skills inherent in a college curriculum (Paskow, 1988). To this end, the American Association for Higher Education (AAHE) has been in the outcomes assessment and institutional effectiveness vanguard. AAHE has played a proactive part in this movement by hosting their Annual Conference on Assessment (the seventh of which 
took place this summer in Miami), publishing both Change and the AAHE Bulletin, and supporting numerous related conferences and projects each year.

One might ask then should collegiate aviation programs be concerned with the increased emphasis on outcomes assessment by the regional associations? Won't the accreditation, or the reaffirmation of accreditation of the other academic programs on the campus insure that the aviation program, which is not usually very large in comparison, will be impervious to the regional review? Furthermore, since many of collegiate academic programs have been approved by the Federal Aviation Administration (FAA) and such programs are specifically taught to meet performance objectives contained in the appropriate Federal Aviation Regulations (FARs), won't that suffice? Well, Kiteley (1991) perhaps stated the issue best:

Assessment now is a way of life in higher education in that we must not only deliver the appropriate content to our students, we must measure the learning outcomes to ensure that the students that are leaving our campuses have the necessary knowledge and skills to meet industry and society expectations. We need to strengthen networking with industry through advisory committees, formalized graduate follow-up surveys that ensure that we not only have a current and relevant curriculum today, but one that stays current and relevant to the needs of a dynamic changing industry. (p. 3)

The new thinking then appears to be how are we going to make such changes and how are we going to insure that collegiate aviation programs can pass the scrutiny of the regional accreditation associations now and in the future.

\section{Accreditation Requirements}

Traditionally, most collegiate aviation programs have blended a highly technical academic program into a somewhat acceptable academic major. Although on many campuses, the convincing of academic peers that aviation is a viable collegiate pursuit has not come easy. As if these forays haven't been enough, there is another fight just over the horizon for colleges and universities in the Southern United States. The issue of institutional effectiveness is an extremely important one to the Southern Association of Colleges and Schools (SACS) and is so critical to the accreditation process that a Resource Manual on Institutional Effectiveness (SACS, 1989) was developed by the association to assist colleges and universities in interpreting Section III of the Criteria for Accreditation (SACS, 1991) of the Commission on Colleges of SACS. Although James T. Rogers stated that the "... inclusion of the section on 'Institutional Effectiveness' is a very modest first step" (p. ii), this document provides institutions with a comprehensive, thought provoking treatise on how to effective interpret the five "must" statements concerning institutional effectiveness. These five statements indicate that institutions that wish to be accredited or reaccredited must:

1. Establish adequate procedures for planning and evaluation.

2. Define [the institution's] expected educational results.

3. Describe how the achievement of these results will be ascertained.

4. Engage in continuing study, analysis and appraisal of their purposes, policies, procedures, and programs.

5. Evaluate the institutional research function. 
In addition, there are eight "should" statements that should be considered advisory and not prescriptive in nature. Included among these are suggestions that relate to the planning and evaluation process that institutions may employ in addressing the issue of institutional effectiveness.

Now, does this impact collegiate aviation programs? Yes, quite significantly since when the parent institutior is being evaluated for accreditation, so is the flight line, the aerospace classroom, and the repair station. It will be virtually impossible to escape the view of the visiting team. While this may not sound like too much of a chore for those who are comfortable with outcomes assessment already, others that are just getting into the institutional effectiveness arena may be facing some difficult times. In addition, on those campuses where the aviation program has to virtually fight for academic recognition every step of the way, there will be many exciting days ahead.

\section{Developing an Institutional Effectiveness Program}

How best to prepare and proceed with developing an institutional effectiveness program? Since such a program will usually be a campus-wide program, it would seem appropriate to become heavily involved with your institution's institutional effectiveness efforts right from the beginning. However, if you are in a leadership role in the process or wish to develop an effectiveness program solely for the benefit of your academic unit, a review of the assessment process is appropriate.

\section{The Assessment Process}

The central questions in the assessment process are (a) what body of knowledge is required to adequately convey a specific academic program, (b) how can that knowledge be delivered in the most appropriate instructional package, and (c) how do educators know that they are educating students effectively? Fitzgibbons (1981) and Telfer and Biggs (1988) refer to these three questions respectively as the matter, the manner, and the outcomes of education. If we then set out overtly to improve the matter, manner, and outcomes by using such a model (Mentkowski \& Loacker, p. 49, 1985), we have a very embryonic but effective assessment model. Figure 1 illustrates two concepts that are central to the assessment process, involvement of faculty as well as students and a goal oriented decision making model. The decision making section shows that the learning experience has several distinct components goals, criteria, performance, observation, judgment, and feedback. The learning event encompasses the first three of these components followed by observation which culminates in a decision about goal achievement and possible modification.

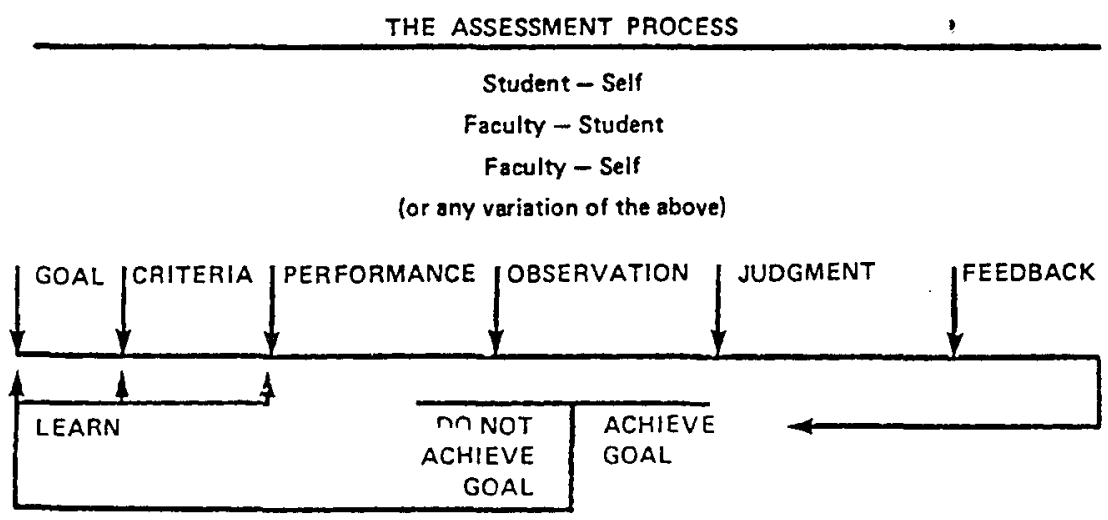

Figure 1. Components of the Assessment Process 
Additionally, there are also several recommendations of a non-instructional nature that must be considered in assessment plan development. The North Central Association of Colleges and Schools (1991) has defined the assessment process as possessing ten distinct characteristics. These ten characteristics indicate that the assessment program:

1. Flows from the institution's mission.

2. Has a conceptual framework.

3. Has faculty ownership/responsibility.

4. Has institution-wide support.

5. Uses multiple measures.

6. Provides feedback to students and the institution.

7. Is cost effective.

8. Does not restrict or inhibit goals of access, equity, and diversity established by the institution.

9. Leads to improvement.

10. Has a process in place for evaluating the assessment program.

While the steps outlined in Figure 1 and included in the 10 characteristics of assessment offered by North Central above seem to encompass most of the components of a rudimentary assessment program, collegiate aviation programs have some unique attributes that must be accounted for in establishing any institutional effectiveness paradigm. The most significant of those attributes is that there may be a number of major academic programs within an institution that are approved by the FAA. Such programs might be the FAR 141 flight instruction curriculum, an aviation maintenance technician school certificate issued under FAR 147, or a certified repair station with associated ratings. Most of these certificates specify the manner in which certificates are issued and maintained, what facilities and equipment are required as part of the instructional program, the minimum experience levels and certification of instructional personnel, the curriculum, and the minimum measurable performance level for each flight, ground, or repair operation. However, such a level of performance may not be in and of itself totally acceptable for accreditation. Just meeting FARs or complying with the Practical Test Standards may not suffice; you may have to, in the process of self-study in preparation for accreditation, set out on a course of having to re-evaluate your whole academic program from the bottom up.

Performance Objectives. If you must proceed from the beginning, one fundamental activity that is germane to the education process is the development of performance objectives for all courses, any instructional sequences, and the academic major(s) that are part of the aviation program. A performance objective (be it called a learning or behavior objective or even an intended learning outcome) is "an educational goal that specifies the learned behavior a student is to exhibit after a learning episode (lesson or series of lessons). The objective usually details the conditions under which the learning is to occur and the level of performance expected" (Telfer \& Biggs, 1988, p. 152). Most performance objectives take the form of: At the completion of the course (lesson, task, or even term), the student should be able to do a specific things under a certain regime and to such a level of performance.

To write a performance objective the first step is to determine in which domain of learning the activity is centered, the cognitive domain (knowledge), the affective domain (values), or the psychomotor domain (skills). Specific references for the cognitive domain may be found in Bloom (1952), for the affective domain in Krathwohl (1964), and in Simpson (1972) for the psychomotor domain. The second step is to determine the major category within each domain that best indicates the level of performance expected for the objective. Once the level has been determined, the third step is to select the action 
verb that best exemplifies the type of activity the learner will pursue. Finally, the action verb is combined with criteria and condition that relate to the specific activity.

Many faculty members may need assistance in preparing such performance objectives. A hands-on, userfriendly, and step-by-step method of developing performance objectives using action verbs, criteria, and conditions could be an appropriate direction. Perhaps a series of inservice workshops on an institution wide basis could accomplish the preparation of such objectives in a uniform format.

Course Syllabi and Outlines. Additionally, this may be an appropriate time to review each academic offering, prepare uniform course syllabi, and do a general housecleaning in the paperwork department. The accreditation teams will be very interested in whether there is uniformity within the institution. The process of accreditation at institutions that have branch campuses, foreign campuses, or programs housed at military bases and taught by adjunct faculty can be somewhat difficult. In addition, if there are multiple sections of a class taught by different instructors, syllabi and course outlines should be as consistent as possible. There is need for the institution to integrate horizontal communication among wide spread academic entities since the accreditation associations view their efforts as being directed at one institution no matter how many different sites are involved.

\section{Conclusions}

It seems clear that the assessment of educational goals, particularly as part of the accreditation process by the regional association is now a fact of academic life. In fact, it is an integral part of the process in the SACS region and will surely become more important in all areas of the country. At the core of the issue, however, is still the questions of what skills, knowledge, and values does a well educated graduate possess and does a college education make a difference. Addressing such concerns must be done sooner rather than later, at least in the minds of the regional accrediting associations.

Many of the problems associated with the development of assessment procedures to meet the criteria for accreditation may seem almost insurmountable in the beginning but these challenges are not impossible. Faculty will soon begin to talk about outcomes assessment; most individuals will begin to see ways that will improve their teaching, provide their students with a more meaningful educational experience, and better prepare graduates for the future. Hemphill (1991) perhaps illustrates the point best in that:

faculty actually have the most to gain from assessment for two reasons. First, assessment emphasizes the academic mission if the institution. As a result of the planning that must precede assessment, academic needs emerge in the forefront of the institutional decision-making process. Second, assessment focuses attention on the qualitative dimension that is normally given heavy emphasis due to enrollment-driven funding formulas. It is possible that, through assessment, the interest of faculty and the need of the public to improve the quality of higher education will merge into one unified effort. Faculty members have a common interest in supporting and funding assessment as a promising way to achieve our primary goal of the providing education of the highest quality. (p. 13)

Outcomes assessment will then benefit not only the student but the faculty as well. Additionally, the institution will profit by providing a more meaningful and relevant educational experience. Perhaps then assessing educational outcomes as a component of the accreditation process is not a hurdle after all but what we really want to do anyway! 


\section{References}

Bloom, B. S. (1956). Taxonomy of educational objectives: Handbook 1, Cognitive domain. New York: McKay.

Fitzgibbons, R. (1981). Making educational decisions: An introduction to philosophy of education. New York: Harcourt Brace Jovanovich.

Hemphill, R.W. (1991). Assessment: Faculty have the most to gain. Assessment Update, pp. 13 - 14.

Kiteley, G. (1991). Paper presented at Dowling College Seminar. Opelika, AL: University Aviation Association.

Krathwohl, D. R. (1964). Taxonomy of educational objectives: Handbook Il, Affective domain. New York: McKay.

Mentkowski, M., \& Loacker, G. (1985). Assessing and validating the outcomes of college. In Ewell, P.T. (Ed.). Assessing educational outcomes (pp. 47-64). San Francisco, CA: Jossey-Bass.

North Central Association of Colleges and Universities (1991). Ten characteristics of an assessment program. Chicago, IL: Author.

Paskow, J. (Ed.). (1988). Assessment programs and projects: A directory. Washington, DC: American Association for Higher Education.

Simpson, E. J. (1972). The classification of educational objectives in the psychomotor domain. The psychomotor domain: Vol. 3. New York: Gryphon House.

Southern Association of Colleges and Schools (1989). Resource manual on institutional effectiveness (2nd. ed.). Atlanta, GA: Author.

Southern Association of Colleges and Schools (1991). Criteria for accreditation (7th. ed.). Atlanta, GA: Author.

Telfer, R., \& Biggs, J. (1988). The psychology of flight training. Ames, IA: Iowa State University Press.

Thrash, P. (1991, November/December). In support of more active regional accreditation (Letter to the editor). Change pp. 6-7.

Weiner, S. (1991, November/December). In support of more active regional accreditation (Letter to the editor). Change, p. 7. 